\title{
Smoking Cessation Ameliorates Microalbuminuria With Reduction of Blood Pressure and Pulse Rate in Patients With Already Diagnosed Diabetes Mellitus
}

\author{
Kunio Hieshima ${ }^{\text {a, d }}$, Tomoko Suzuki ${ }^{\text {a }}$, Seigo Sugiyama ${ }^{\text {a, b }}$, Noboru Kurinami ${ }^{\text {a }}$, Akira Yoshida ${ }^{\text {a }}$ \\ Fumio Miyamoto $^{\text {a }}$, Keizo Kajiwara ${ }^{\text {a, b }}$, Tomio Jinnouchia ${ }^{\text {a b }}$, c, Hideaki Jinnouchia, b, c
}

\begin{abstract}
Background: Smoking cessation in newly diagnosed type 2 diabetes patients is reported to be associated with amelioration of metabolic parameters and blood pressure (BP), and the reduction of microalbuminuria. The aim of this study is to demonstrate changes in BP, pulse rate (PR), and microalbuminuria in already diagnosed diabetes patients who quit smoking.
\end{abstract}

Methods: We retrospectively evaluated diabetes outpatients who were habitual smokers, and who visited to our smoking cessation clinic. Patients were divided into two groups based on their smoking status at the termination of a 3-month smoking cessation program (smoking cessation group and smoking group), and analyzed systolic and diastolic BPs, PR, HbAlc, and body weight at the start date, and at $1,3,6$, and 12 months thereafter. The urinary albumin-to-creatinine ratio was also measured at the start date and at 12 months.

Results: Thirty-five patients met our criteria. Mean diabetes duration was 12 years. Eighteen patients (52\%) quit smoking. Success or failure of smoking cessation depended on nicotine dependence rather than good or bad glycemic control. Both BP and PR decreased significantly after 1 month or later in the smoking cessation group without worsening $\mathrm{HbA} 1 \mathrm{c}$, while both parameters did not show any changes in the smoking group. Microalbuminuria was also ameliorated significantly at 12 months compared with that at the start date in the smoking cessation group $(95.8 \pm 92.9 \mathrm{mg} / \mathrm{gCr}$ vs. $75.5 \pm 96.3 \mathrm{mg} / \mathrm{gCr}$, $\mathrm{P}=0.0059$ ), while it did not show a significant change in the smoking group. (61.9 $\pm 43.5 \mathrm{mg} / \mathrm{gCr}$ vs. $97.7 \pm 90.4 \mathrm{mg} / \mathrm{gCr}, \mathrm{P}=0.1039)$.

Conclusions: Smoking cessation might cause a reduction in chronic

Manuscript submitted March 9, 2018, accepted March 21, 2018

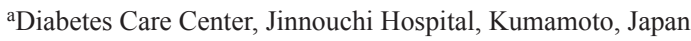

${ }^{\mathrm{b}}$ Cardiovascular Division, Diabetes Care Center, Jinnouchi Hospital, Kumamoto, Japan

'Division of Preventive Cardiology, Department of Cardiovascular Medicine, Kumamoto University Hospital, Kumamoto, Japan

${ }^{\mathrm{d} C o r r e s p o n d i n g ~ A u t h o r: ~ K u n i o ~ H i e s h i m a, ~ D i a b e t e s ~ C a r e ~ C e n t e r, ~ J i n n o u c h i ~}$ Hospital, 6-2-3 Kuhonji, Chuo-ku, Kumamoto 862-0976, Japan.

Email: hieshima@jinnouchi.or.jp

doi: https://doi.org/10.14740/jocmr3400w kidney disease progression through ameliorating microalbuminuria without metabolic adverse effects in patients already diagnosed with diabetes mellitus.

Keywords: Smoking cessation; Diabetes; Nicotine dependence; Blood pressure; Pulse rate; Microalbuminuria

\section{Introduction}

Cigarette smoking is the most important risk factor for development of cardiovascular events $[1,2]$ and also for development and progression of chronic kidney disease (CKD) [3-12]. Diabetes was also shown to be a risk factor for CKD, and patients with diabetes have three to four times more CKD complications compared with those without diabetes [13]. Because diabetic kidney disease (DKD) is a predominant cause of end stage renal disease (ESRD), prevention and treatment of DKD has been emphasized in diabetes patient management [14]. Diabetes patients have a high incidence of hypertension [15, 16], which is also a cause and consequence of CKD. Recent population-based cohort studies showed that hypertension is a cause of ESRD in both sexes [4, 17-21]. Although cigarette smoking has been shown to affect development of hypertension, the long-term effect of cigarette smoking on blood pressure (BP) is currently not well defined [22].

Voulgari reported that smoking cessation in newly diagnosed type 2 diabetes patients is associated with amelioration of metabolic parameters, BP, and the reduction of microalbuminuria [23]. In this research, we retrospectively assessed whether smoking cessation in patients already diagnosed with diabetes affects BP, pulse rate (PR), microalbuminuria, body weight (BW), and $\mathrm{HbA1c}$, and evaluated the benefit of reducing the development of $\mathrm{CKD}$ in the patients with long-standing diabetes.

\section{Patients and Methods}

\section{Study design}

We analyzed 55 diabetes outpatient subjects who followed the 
Table 1. Baseline Characteristics of Study Participants for the Overall Sample and Sub-Groups

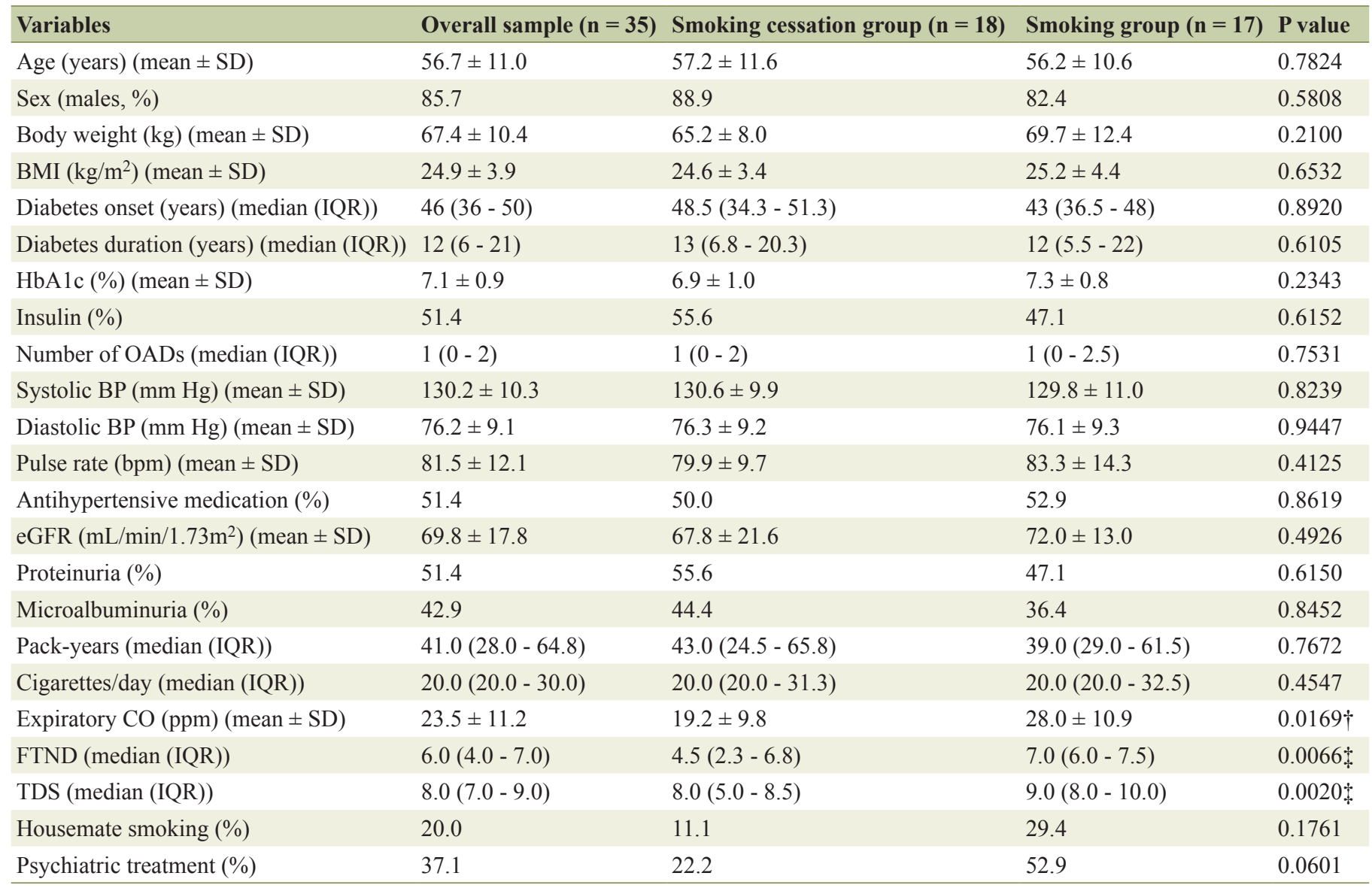

BMI: body mass index; OAD: oral anti-diabetes drug; BP: blood pressure; CO: carbon monoxide; FTND: Fagerstrom Test for Nicotine Dependence; TDS: Tobacco Dependence Screener. $† P<0.05, \ddagger P<0.01$

3-month smoking cessation program at the Jinnouchi Hospital Diabetes Care Center between April 2013 and August 2015. It was assumed that patients who participated in the smoking cessation program met the following conditions for smokers: 1) intending to discontinue smoking promptly; 2) diagnosed with nicotine dependence using the Tobacco Dependence Screener (TDS) (more than 5 out of 10 points for the TDS score); 3) history of smoking more than 10 pack-years; 4) signed agreement to receive smoking cessation treatment. Among them, 35 subjects were selected for further analysis (30 males, five females; six with type 1 diabetes, 29 with type 2 diabetes; 32 receiving varenicline treatment, and three receiving nicotine replacement therapy), who had no change in their dose of both oral antihyperglycemic drugs and antihypertensive drugs, and they were within $\pm 10 \%$ of the total daily dose of insulin for 12 months. These 35 subjects were divided into two groups: those who stopped smoking (the smoking cessation group) and those who continued smoking (the smoking group), based on their smoking status at the end of the 3-month program. We measured the concentration of expiratory carbon monoxide (CO) at baseline, 1 month, and at the end of the program, as well as systolic and diastolic BPs, PR, BW, and HbAlc at baseline and at $1,3,6$, and 12 months after beginning the program.
Albuminuria was measured at baseline and at 12 months, and BP was measured once after a 5-min rest, using the same automatic sphygmomanometer. The concentration of expiratory $\mathrm{CO}$ was measured using a MicroCO ${ }^{\mathrm{TM}}$ carbon monoxide monitor (CareFusion UK 232 Ltd., UK). A participant was considered abstinent from cigarettes if he or she both self-reported cigarette abstinence and had an exhaled CO less than $7 \mathrm{ppm}$ at 3 months. Albuminuria was measured at baseline and at 12 months. We analyzed subjects for microalbuminuria (30 to 300 $\mathrm{mg} / \mathrm{gCr}$ ) at baseline.

All patients were informed about the study procedure. Written informed consent was obtained from all patients before participating in the study. This study was performed in accordance with the ethical standards detailed in the Declaration of Helsinki. The study protocol was approved by the Hospital Ethics Committee.

\section{Statistical analysis}

Data were statistically analyzed using JMP 10.0.2 software (SAS Institute Inc., Cary, NC). Categorical variables are presented with their frequency distribution. The association be- 


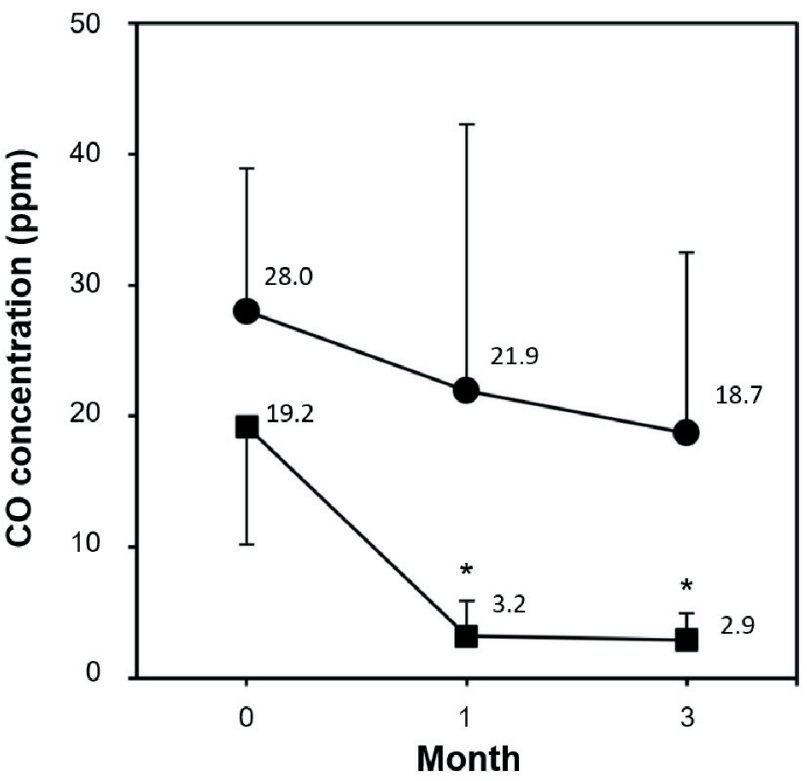

Figure 1. Comparison of $\mathrm{CO}$ concentration during 3-month smoking cessation program between smoking cessation group and smoking group. Data are represented as mean \pm SD. Asterisk denotes $P$ $<0.0001$ as compared to the baseline level; (filled square) smoking cessation group and (filled circle) smoking group.

tween categorical variables was evaluated using the $\chi^{2}$ test or Fisher's exact test. To identify normality in continuous variables, the Shapiro-Wilk test was used. Continuous variables are shown as the mean \pm standard deviation (SD). If continuous variables showed a non-normal distribution, they were summarized using the median interquartile range (IQR). If normal distribution was demonstrated, the Student's $t$-test was used to compare the groups. If normal distribution was not demonstrated, the Mann-Whitney $U$ test was used. We compared the average of the continuous variables between the baseline and follow-up time points using the Student's $t$-test for paired samples, or the Wilcoxon non-parametric test for variables that showed non-normal distribution. Differences between the two groups at baseline were analyzed using unpaired $t$-tests for continuous variables and $\chi^{2}$ tests for categorical variables. Paired $t$-tests were used for within-group comparisons, and unpaired $t$-tests were used for between-group comparisons. The results were considered statistically significant when $\mathrm{P}<0.05$.

\section{Results}

Fifty-five diabetes outpatients who were habitual smokers attended our hospital for smoking cessation between April 2013 and August 2015. We divided them into two groups according to their smoking status at the end of a 3-month program; the smoking cessation group comprised 27 subjects and the smoking group comprised 28 subjects. Among them, the subjects who did not change both oral antihyperglycemic drugs and antihypertensive drugs for 12 months, and, for insulin users, those whose insulin dose changed within $\pm 10 \%$ of the total daily dose at baseline dosage compared with the dose at 12 months were further analyzed. Thus, there were 35 patients who met the criteria. The final smoking cessation group included 18 patients (16 males, two females; four with type 1 diabetes, 14 with type 2 diabetes; 18 taking varenicline treatment), and the final smoking group included 17 patients (14 males, three females; two with type 1 diabetes, 15 with type 2 diabetes; 14 taking varenicline treatment, and three taking nicotine replacement therapy).

The patients' clinical baseline characteristics are shown in Table 1. The mean age of the 35 patients was 56.7 years, $85.7 \%$ were male, the mean BMI was $24.9 \mathrm{~kg} / \mathrm{m}^{2}, \mathrm{HbAlc}$ was $7.1 \%$, the microalbuminuria-positive rate was $42.9 \%$, the median pack-years were 41.0, and cigarettes per day were 20.0. There were no significant differences in the measured characteristics between the smoking cessation group and the smoking group at baseline except indices showing nicotine dependency, such as expiratory CO concentration (19.2 $\pm 9.8 \mathrm{ppm}$ vs. $28.0 \pm 10.9 \mathrm{ppm}$, respectively, $\mathrm{P}=0.0169)$, Fagerstrom Test for Nicotine Dependence (FTND) (5.5 (3.0 - 7.0) vs. 7.0 (6.0 - 7.5), respectively, $\mathrm{P}=0.0066$ ), and the Tobacco Dependence Screener (TDS) (8.0 (5.5 - 9.0) vs. 9.0 (8.0 - 10.0), respectively, $\mathrm{P}=0.0020$ ). FTND and TDS are considered to be a physical and psychological dependency on nicotine, respectively. Packyears and cigarettes per day were not significantly different between the smoking cessation and smoking groups, which was unexpected (43.0 (24.5 - 65.8) pack-years vs. $39.0(29.0-61.5)$ pack-years, $\mathrm{P}=0.7672 ; 20.0(20.0-31.3)$ cigarettes/day vs. 20.0 (20.0 - 32.5) cigarettes/day, $\mathrm{P}=0.4547$, respectively). Neither patients with housemate smokers nor those with psychiatric disorders had significant changes between groups. A decreasing trend was shown in patients with each factor ( $22.2 \%$ vs. $52.9 \%, \mathrm{P}=0.0601 ; 11.1 \%$ vs. $29.4 \%, \mathrm{P}=0.1761$, respectively) in the smoking cessation group compared with the smoking group, although each factor has been reported to be lower in those who could quit smoking.

The expiratory $\mathrm{CO}$ concentration significantly decreased in the smoking cessation group both at 1 and 3 months compared with baseline, whereas no significant changes were seen in the smoking group, which showed a slightly decreasing trend (Fig. 1). In the smoking cessation group, systolic BP significantly decreased by $-7.0 \mathrm{~mm} \mathrm{Hg}$ at 1 month $(\mathrm{P}=0.0346)$ and -9.1 $\mathrm{mm} \mathrm{Hg}$ at 12 months $(\mathrm{P}=0.0196)$ (Fig. 2a). Each systolic BP result at 1 month or thereafter showed no significant changes. Diastolic BP also significantly decreased in the smoking cessation group by $-4.2 \mathrm{~mm} \mathrm{Hg}$ at 1 month $(\mathrm{P}=0.0379)$ and -5.9 $\mathrm{mm} \mathrm{Hg}$ at 12 months $(\mathrm{P}=0.0019)$ (Fig. 2b). Each diastolic $\mathrm{BP}$ after 1 month showed no significant change. PR also significantly decreased in the smoking cessation group by -5.1 bpm at 1 month $(\mathrm{P}=0.0019)$ and $-6.7 \mathrm{bpm}$ at 12 months $(\mathrm{P}=$ 0.0243; Fig. 2c). Each PR after 1 month showed no significant changes. Conversely, BPs and PR had no significant changes at any point in the smoking group (Fig. 2a-c).

In those who had microalbuminuria at baseline, neither the ratio nor the average differed significantly between groups (44.4\% $(\mathrm{n}=8)$ vs. $36.4 \%(\mathrm{n}=7), \mathrm{P}=0.8452$ (Table 1); 95.8 $\pm 92.9 \mathrm{mg} / \mathrm{gCr}$ vs. $61.9 \pm 43.5 \mathrm{mg} / \mathrm{gCr}, \mathrm{P}=0.3774$ (Fig. 3), respectively). After 12 months, microalbuminuria was amelio- 

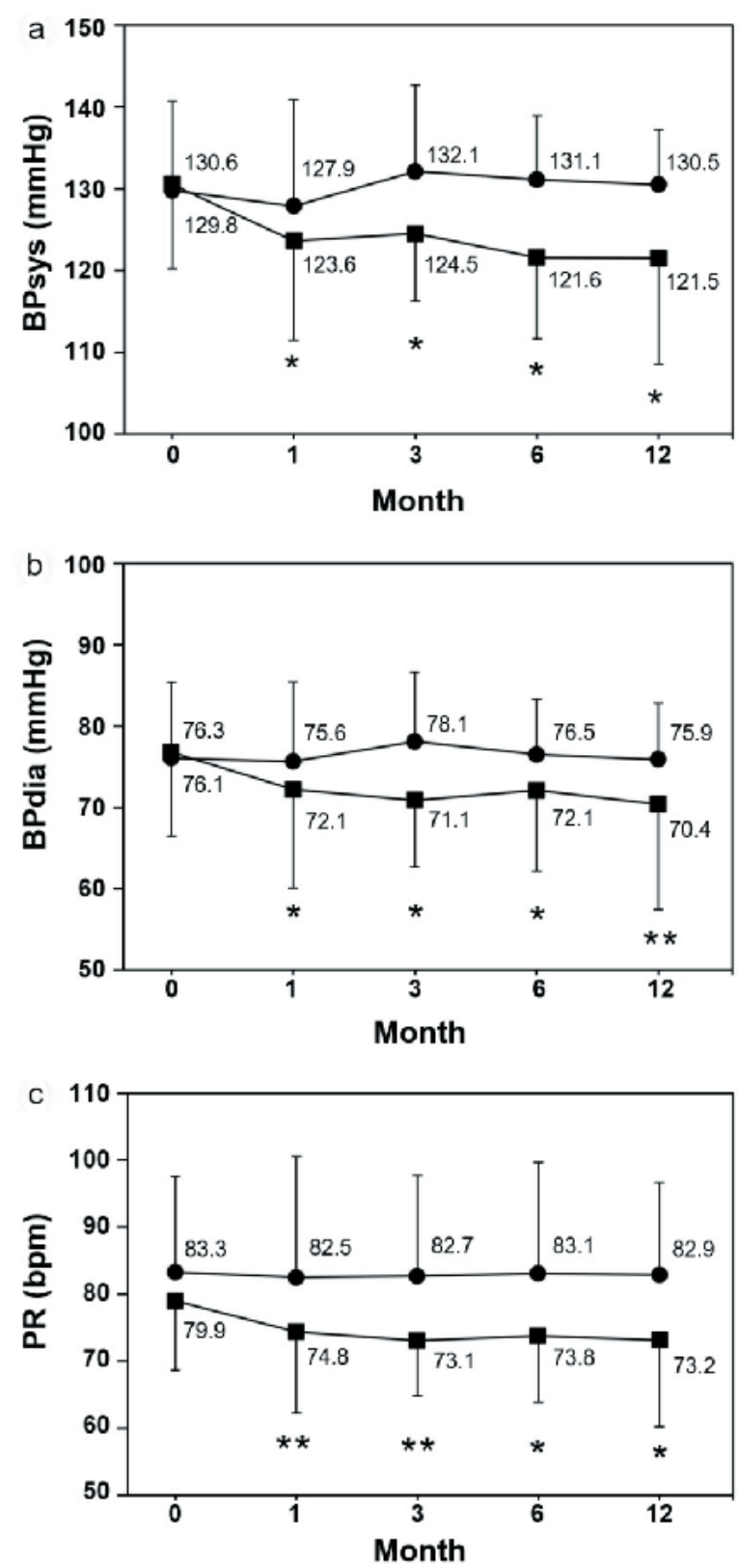

Figure 2. Changes of systolic and diastolic blood pressures and pulse rate. (a) Systolic blood pressure (BPsys). (b) Diastolic blood pressure (BPdia), (c) Pulse rate (PR). Data are represented as mean \pm SD. Single and double asterisks denote $P<0.05$ and $P<0.01$, respectively as compared to the baseline level; (filled square) smoking cessation group and (filled circle) smoking group.

rated significantly in the smoking cessation group, but not in the smoking group $(75.5 \pm 96.3 \mathrm{mg} / \mathrm{gCr}(-19.7 \mathrm{mg} / \mathrm{gCr}), \mathrm{P}=$ 0.0059 vs. $97.7 \pm 90.4 \mathrm{mg} / \mathrm{gCr}(+35.8 \mathrm{mg} / \mathrm{gCr}), \mathrm{P}=0.1039$, respectively) (Fig. 3a, b). Estimated glomerular filtration rate (eGFR) at baseline did not differ significantly $(67.8 \pm 21.6 \mathrm{vs}$. $72.0 \pm 13.0, \mathrm{P}=0.4926$; Table 1). eGFR after 12 months also did not change in each group $(65.3 \pm 20.0, \mathrm{P}=0.4477$ vs. 69.0 $\pm 15.8, \mathrm{P}=0.2591$, respectively).
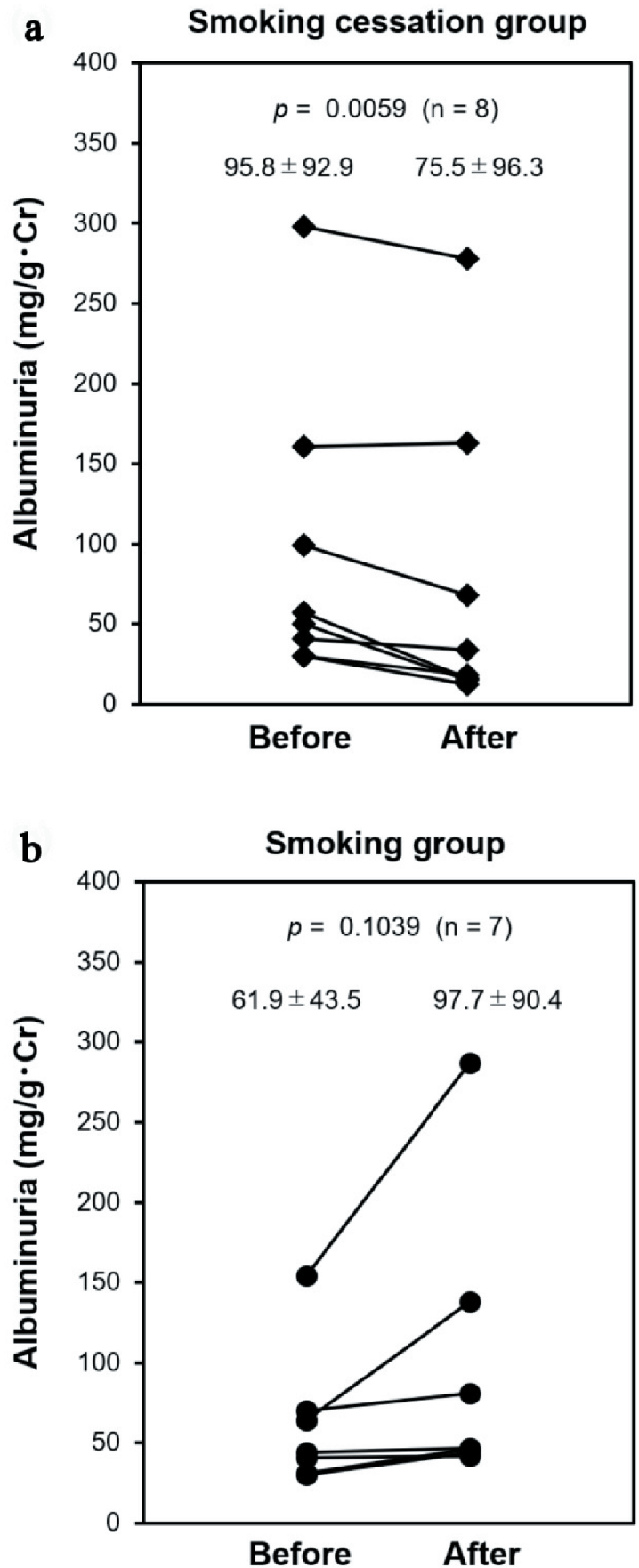

Figure 3. Changes of albuminuria. Subjects who had microalbuminuria (30 to $300 \mathrm{mg} / \mathrm{gCr}$ ) at baseline (Before) were followed at 12 months (After); (a) Smoking cessation group (filled diamond) and (b) smoking group (filled circle).

BW gradually increased after beginning the smoking cessation program in both groups. There was a significant weight gain after 3 months in the smoking cessation group and after 6 months in the smoking group. The final weight gains at 12 months were $1.9 \mathrm{~kg}$ and $1.4 \mathrm{~kg}$, respectively. However, HbA1c 

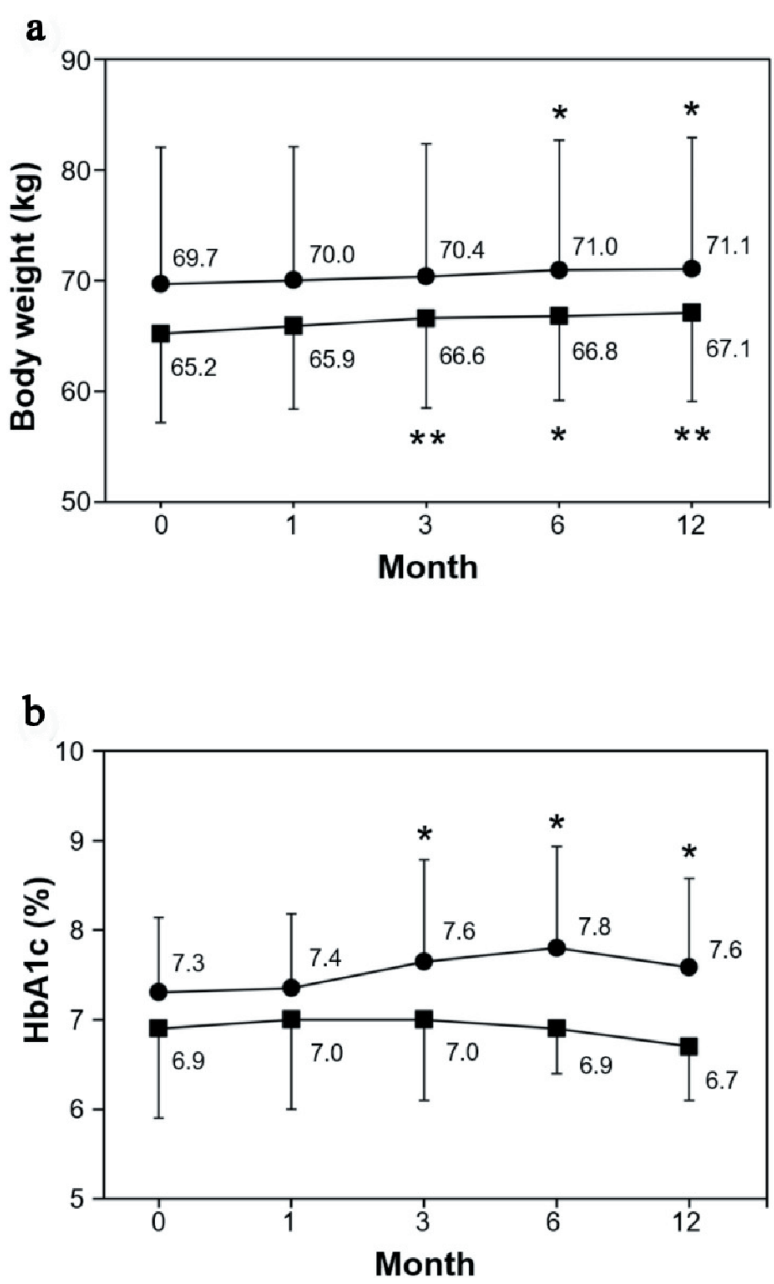

Figure 4. Changes of body weight and $\mathrm{HbA1c}$. (a) Body weight (kg). (b) $\mathrm{HbA} 1 \mathrm{c}(\%)$. Data are represented as mean \pm SD. Single and double asterisks denote $\mathrm{P}<0.05$ and $\mathrm{P}<0.01$, respectively as compared to the baseline level; (filled square) smoking cessation group and (filled circle) smoking group.

did not change significantly throughout the study period in the smoking cessation group in those whose medication did not change, whereas it significantly increased at 3 months and thereafter in the smoking group (Fig. 4a, b).

\section{Discussion}

In this study, we demonstrated that smoking cessation ameliorates microalbuminuria, with a reduction in BP and PR and without worsening diabetes control in patients with already diagnosed diabetes. Cigarette smoking results in various adverse effects such as sympatheticotonic effects by nicotine (i.e., elevated $\mathrm{BP}$, increased $\mathrm{PR}$, and vasoconstriction), reduction in oxygen supply by $\mathrm{CO}$, and vascular endothelial dysfunction $[1,2]$. To date, in non-diabetes patients, an immediate beneficial effect on BP was reported when they discontinued smoking, and even 1-week short-term smoking cessation significantly decreased daytime BP and heart rate [24]. Additionally, BP, heart rate, and microalbuminuria were reported to improve when diabetes patients discontinued smoking just after the onset of diabetes and abstained from smoking for 1 year [23]. Therefore, regardless of the diabetes duration, smoking cessation may result in a positive effect for circulatory system parameters, leading to amelioration of microalbuminuria in just 1 year alone.

It is reported that the ex-smokers have a higher incidence of hypertension than never-smokers [25]. Weight gain after smoking cessation is thought to be associated with hypertension [26]. However, it is unknown at present when people who quit smoking show a tendency toward hypertension after smoking cessation. Subjects who quit smoking in this study had a significant BW gain by the 12-month follow-up. However, there was no significant increase in BP. A recent metaanalysis including 62 randomized controlled trials concluded that smoking cessation was associated with a mean weight gain of $4-5 \mathrm{~kg}$ after 1 year of abstinence [27]. Because our weight gain data at 12 months in the smoking cessation group showed an increase of about $1.9 \mathrm{~kg}$, which was less than that of the meta-analysis, the weight gain might not cause hypertension. Careful management of the BP is required in the smoking cessation group to prevent the complication of hypertension because it is possible that the patients' BP will gradually increase sometime in the future.

Smoking cessation is found to be more effective than oral medicines such as aspirin, antihypertensive agents, and statins [28], and a reduction in the risk of cardiovascular diseases appears relatively soon thereafter [29]. This study showed that the significant decrease of BP and PR in the smoking cessation group appeared within the first month, meaning that this effect of smoking cessation was realized almost immediately. Because hypertension is the important risk factor for CKD exacerbation [30], improvement of BP from an early stage of CKD may result in a benefit that would be extremely useful in suppression of CKD progression. In a meta-analysis of 20 RCTs, including 52,400 patients, for each tertile decrease in achieved BP, there was a relative risk reduction of $26 \%$ for progression to ESRD [31]. Similarly, in a meta-analysis of 84 randomized and non-randomized trials in CKD patients, for each $10-\mathrm{mm} \mathrm{Hg}$ decrease in mean arterial pressure, there was an improvement of $0.18 \mathrm{~mL} / \mathrm{min} / 1.73 \mathrm{~m}^{2} /$ month in the GFR rate of loss [32]. In our data, there was an approximately $9 \mathrm{~mm}$ $\mathrm{Hg}$ decrease in systolic BP in the smoking cessation group, suggesting an improvement in the eGFR reduction rate in the future, although it has not yet been confirmed.

Microalbuminuria is a known early predictive risk factor for renal disease. Briefly, patients with microalbuminuria have a 3.3-fold (95\% CI 2.1 - 5.1) higher multivariable-adjusted risk of renal events (i.e., death as a result of kidney disease, requirement for dialysis or transplantation, or doubling of serum creatinine to $>200 \mu \mathrm{mol} / \mathrm{L}$ ) [33]. The renal tissue of diabetes patients with microalbuminuria already shows abnormalities [34]. Additionally, there is the case in which a nodule and expansion in the mesangial regions appear in renal tissues in diabetes patients even with normoalbuminuria [34]. Therefore, when the diabetes patients have microalbuminuria, we should be aware of an impending crisis because DKD 
pathological changes begin without any symptoms. Additionally, smoking exacerbates CKD, and smoking cessation that can improve microalbuminuria, such as in our study, is a vital treatment to suppress nephropathy and as a dialysis precautionary measure. Thus, all diabetes patients who are habitual smokers should be aggressively encouraged to quit smoking. Stricter counseling may be necessary to protect against the development of CKD.

Earlier reports demonstrated that if patients with microalbuminuria can achieve appropriate blood glucose levels, BP, and lipid management, they can delay the exacerbation of CKD $[35,36]$. Our findings showed that if there is a significant decrease in BP, even if blood glucose is not improved, microalbuminuria could be improved. The importance of a short-term BP-lowering effect was reconfirmed. As mentioned above, because ex-smokers have a tendency towards hypertension, we should be aware that BP management including BW control is connected directly to microalbuminuria countermeasures.

Generally, smoking cessation causes weight gain through both appetite and metabolic improvements. A recent report showed that an increased risk of diabetes was observed among individuals who newly quit smoking compared with neversmokers among men (odds ratio (OR), 1.42; 95\% CI, 1.03 1.94) and women (OR, 2.84; 95\% CI, 1.53 - 5.29) [37]. Our quitters did not show worsening $\mathrm{HbAlc}$ but there was an increase in BW. We do not understand why, but possible causes are: 1) the short observational period in our study compared with the report above, where the authors monitored for at least 5 years; 2) possibility that the weight gain was not enough to increase insulin resistance; 3) improvement of insulin resistance by smoking cessation; 4) continuous encouragement of aggressive exercise; and 5) repeated counseling about the importance of diet therapy. For glycemic control, quitters should be further followed up, maintaining an aggressive lifestyle intervention.

At the beginning of this study, we hypothesized that smokers who did not quit had poorer metabolic factors, such as worse HbA1c, and higher BW and BMI than those who quit smoking. However, only nicotine dependency was consistent between the groups at the baseline, demonstrating that to prevent complications, the poorer control that patients have, the better treatment they should pursue irrespective of metabolic status. The TDS was the most significant predictive factor for smoking cessation between quitters and non-quitters in this study, and was originally developed to measure the psychological and behavioral aspects of nicotine dependence according to the Diagnostic and Statistical Manual of Mental Disorders (DSM)-III-R, DSMIV, and International Statistical Classification of Diseases and Related Health Problems (ICD)-10 [38]. To quit smoking, it is important to alter some behaviors, such as the four Ds (delay, drinking water, distract oneself with other activities, and deep breathing) and ACE (avoid, change, and escape, in anticipating or coping with a trigger) [39]. Careful guidance and encouragement are required for those patients who have more than 9 points for their TDS score before treatment.

There are several limitations to the present study. First, the number of subjects in this study was not large. The present findings should be replicated in a future study with a greater number of subjects, conducting a prospective assessment of each parameter. Second, we measured BP only once each vis- it, which may not accurately reflect BP levels and may have resulted in misclassification of our key interpretation. Third, there were few microalbuminuria measurements because of limitations under our health insurance coverage. Because several temporary factors can cause higher-than-normal urinary microalbumin results, such as recent vigorous exercise, hematuria, and dehydration, a larger sample size is needed in a future study to reduce misinterpretations.

In this report, we demonstrated that smoking cessation is one of the most important treatments for diabetes patients because it can reduce complications without worsening diabetes control. There is an increasing incidence and prevalence of kidney failure worldwide, with poor outcomes and a high cost. Smoking cessation is the least expensive method and the best method to reduce the burden of healthcare costs. Continuous and diligent guidance and intensive lifestyle intervention are needed for diabetes patients who are addicted to smoking.

\section{Conclusions}

Smoking cessation might cause a reduction in chronic kidney disease progression through ameliorating microalbuminuria without metabolic adverse effects in patients already diagnosed with diabetes mellitus.

\section{Acknowledgments}

The authors thank Tetsuko Kawashima, Suzuko Harada, Yuki Iwami, and Naomi Takanami for their skillful technical assistance. The authors also thank the Edanz Group (www. edanzediting.com/ac) for editing a draft of this manuscript.

\section{Grant Support}

We have no funding received.

\section{Conflicts of Interest}

The authors declare no conflict of interest.

\section{Author Contributions}

$\mathrm{KH}$ and $\mathrm{HJ}$ were study investigators, contributed to the study design, acquisition and interpretation of data, and critically revised the manuscript. TS, SS, NK, AY, FM, KK and TJ were contributed to the acquisition and interpretation of data, and critically revised the manuscript.

\section{References}

1. U.S. Department of Health and Human Services, Public Health Service. Treating Tobacco Use and Dependence: 
2008 Update. Clinical Practice Guideline. Rockville, MD, 2008.

2. JCS Joint Working Group. Guidelines for Smoking Cessation (JCS 2010) - digest version. Circ J. 2012;76(4):10241043.

3. Tozawa M, Iseki $\mathrm{K}$, Iseki $\mathrm{C}$, Oshiro S, Ikemiya Y, Takishita S. Influence of smoking and obesity on the development of proteinuria. Kidney Int. 2002;62(3):956-962.

4. Yamagata K, Ishida K, Sairenchi T, Takahashi H, Ohba S, Shiigai T, Narita M, et al. Risk factors for chronic kidney disease in a community-based population: a 10-year follow-up study. Kidney Int. 2007;71(2):159-166.

5. Haroun MK, Jaar BG, Hoffman SC, Comstock GW, Klag MJ, Coresh J. Risk factors for chronic kidney disease: a prospective study of 23,534 men and women in Washington County, Maryland. J Am Soc Nephrol. 2003;14(11):2934-2941.

6. Chase HP, Garg SK, Marshall G, Berg CL, Harris S, Jackson WE, Hamman RE. Cigarette smoking increases the risk of albuminuria among subjects with type I diabetes. JAMA. 1991;265(5):614-617.

7. Ikeda Y, Suehiro T, Takamatsu K, Yamashita H, Tamura T, Hashimoto K. Effect of smoking on the prevalence of albuminuria in Japanese men with non-insulin-dependent diabetes mellitus. Diabetes Res Clin Pract. 1997;36(1):5761.

8. Jones-Burton C, Seliger SL, Scherer RW, Mishra SI, Vessal G, Brown J, Weir MR, et al. Cigarette smoking and incident chronic kidney disease: a systematic review. Am J Nephrol. 2007;27(4):342-351.

9. Sawicki PT, Didjurgeit U, Muhlhauser I, Bender R, Heinemann L, Berger M. Smoking is associated with progression of diabetic nephropathy. Diabetes Care. 1994;17(2):126-131.

10. Orth SR, Schroeder T, Ritz E, Ferrari P. Effects of smoking on renal function in patients with type 1 and type 2 diabetes mellitus. Nephrol Dial Transplant. 2005;20(11):24142419.

11. Ejerblad E, Fored CM, Lindblad P, Fryzek J, Dickman PW, Elinder CG, McLaughlin JK, et al. Association between smoking and chronic renal failure in a nationwide population-based case-control study. J Am Soc Nephrol. 2004;15(8):2178-2185.

12. Stengel B, Tarver-Carr ME, Powe NR, Eberhardt MS, Brancati FL. Lifestyle factors, obesity and the risk of chronic kidney disease. Epidemiology. 2003;14(4):479-487.

13. Plantinga LC, Crews DC, Coresh J, Miller ER, 3rd, Saran R, Yee J, Hedgeman E, et al. Prevalence of chronic kidney disease in US adults with undiagnosed diabetes or prediabetes. Clin J Am Soc Nephrol. 2010;5(4):673-682.

14. Tuttle KR, Bakris GL, Bilous RW, Chiang JL, de Boer IH, Goldstein-Fuchs J, Hirsch IB, et al. Diabetic kidney disease: a report from an ADA Consensus Conference. Am J Kidney Dis. 2014;64(4):510-533.

15. Iimura O. Insulin resistance and hypertension in Japanese. Hypertens Res. 1996;19(Suppl 1):S1-8.

16. Henry P, Thomas F, Benetos A, Guize L. Impaired fasting glucose, blood pressure and cardiovascular disease mortality. Hypertension. 2002;40(4):458-463.
17. Klag MJ, Whelton PK, Randall BL, Neaton JD, Brancati FL, Ford CE, Shulman NB, et al. Blood pressure and end-stage renal disease in men. $\mathrm{N}$ Engl J Med. 1996;334(1):13-18.

18. Klag MJ, Whelton PK, Randall BL, Neaton JD, Brancati FL, Stamler J. End-stage renal disease in African-American and white men. 16-year MRFIT findings. JAMA. 1997;277(16):1293-1298.

19. Reynolds K, Gu D, Muntner P, Kusek JW, Chen J, Wu X, Duan X, et al. A population-based, prospective study of blood pressure and risk for end-stage renal disease in China. J Am Soc Nephrol. 2007;18(6):1928-1935.

20. Tozawa M, Iseki K, Iseki C, Kinjo K, Ikemiya Y, Takishita S. Blood pressure predicts risk of developing endstage renal disease in men and women. Hypertension. 2003;41(6):1341-1345.

21. Crews DC, Plantinga LC, Miller ER, 3rd, Saran R, Hedgeman E, Saydah SH, Williams DE, et al. Prevalence of chronic kidney disease in persons with undiagnosed or prehypertension in the United States. Hypertension. 2010;55(5):1102-1109.

22. Halperin RO, Gaziano JM, Sesso HD. Smoking and the risk of incident hypertension in middle-aged and older men. Am J Hypertens. 2008;21(2):148-152.

23. Voulgari C, Katsilambros N, Tentolouris N. Smoking cessation predicts amelioration of microalbuminuria in newly diagnosed type 2 diabetes mellitus: a 1-year prospective study. Metabolism. 2011;60(10):1456-1464.

24. Minami J, Ishimitsu T, Matsuoka H. Effects of smoking cessation on blood pressure and heart rate variability in habitual smokers. Hypertension. 1999;33(1 Pt 2):586590.

25. Li G, Wang H, Wang K, Wang W, Dong F, Qian Y, Gong $\mathrm{H}$, et al. The association between smoking and blood pressure in men: a cross-sectional study. BMC Public Health. 2017;17(1):797.

26. Janzon E, Hedblad B, Berglund G, Engstrom G. Changes in blood pressure and body weight following smoking cessation in women. J Intern Med. 2004;255(2):266-272.

27. Aubin HJ, Farley A, Lycett D, Lahmek P, Aveyard P. Weight gain in smokers after quitting cigarettes: metaanalysis. BMJ. 2012;345:e4439.

28. Critchley JA, Capewell S. Mortality risk reduction associated with smoking cessation in patients with coronary heart disease: a systematic review. JAMA. 2003;290(1):86-97.

29. U.S. Department of Health and Human Services. The health consequences of smoking - 50 years of progress: a report of the Surgeon General. U.S. Department of Health and Human Services, Centers for Disease Control and Prevention, National Center for Chronic Disease Prevention and Health Promotion, Office on Smoking and Health; Atlanta, GA: 2014.

30. Anderson AH, Yang W, Townsend RR, Pan Q, Chertow GM, Kusek JW, Charleston J, et al. Time-updated systolic blood pressure and the progression of chronic kidney disease: a cohort study. Ann Intern Med. 2015;162(4):258265 .

31. Casas JP, Chua W, Loukogeorgakis S, Vallance P, Smeeth 
L, Hingorani AD, MacAllister RJ. Effect of inhibitors of the renin-angiotensin system and other antihypertensive drugs on renal outcomes: systematic review and metaanalysis. Lancet. 2005;366(9502):2026-2033.

32. Maki DD, Ma JZ, Louis TA, Kasiske BL. Long-term effects of antihypertensive agents on proteinuria and renal function. Arch Intern Med. 1995;155(10):1073-1080.

33. Ninomiya T, Perkovic V, de Galan BE, Zoungas S, Pillai A, Jardine M, Patel A, et al. Albuminuria and kidney function independently predict cardiovascular and renal outcomes in diabetes. J Am Soc Nephrol. 2009;20(8):18131821.

34. Ekinci EI, Jerums G, Skene A, Crammer P, Power D, Cheong KY, Panagiotopoulos S, et al. Renal structure in normoalbuminuric and albuminuric patients with type 2 diabetes and impaired renal function. Diabetes Care. 2013;36(11):3620-3626.

35. Diabetes Control and Complications Trial Research Group. Nathan DM, Genuth S, Lachin J, Cleary P, Crofford $\mathrm{O}$, et al. The effect of intensive treatment of diabetes on the development and progression of long-term complications in insulin-dependent diabetes mellitus. N Engl J Med. 1993;329(14):977-986.

36. Gaede P, Vedel P, Parving HH, Pedersen O. Intensified multifactorial intervention in patients with type 2 diabetes mellitus and microalbuminuria: the Steno type 2 randomised study. Lancet. 1999;353(9153):617-622.

37. Oba S, Noda M, Waki K, Nanri A, Kato M, Takahashi Y, Poudel-Tandukar K, et al. Smoking cessation increases short-term risk of type 2 diabetes irrespective of weight gain: the Japan Public Health Center-Based Prospective Study. PLoS One. 2012;7(2):e17061.

38. Kawakami N, Takatsuka N, Inaba S, Shimizu H. Development of a screening questionnaire for tobacco/nicotine dependence according to ICD-10, DSM-III-R, and DSMIV. Addict Behav. 1999;24(2):155-166.

39. Frates EP, Park ER, Evins AE, Fricchione GL. Chronic disease and unhealthy habits: behavioral management. In: Stern TA, Freudenreich O, Smith FA, Fricchione GL, Rosenbaum JF, eds. Massachusetts General Hospital Handbook of General Hospital Psychiatry, 7th ed. New York: Elsevier Inc., 2018, 461-470. 